\title{
Peliosis Hepatis Associated with Idiopathic Restrictive Cardiomyopathy
}

\author{
Katsunobu Yoshioka, Toshihiko Sato, Tomofusa IshiI, Shiro Tanaka, Kiyohide KiokA*, \\ Shigeyoshi Harihara*, Satoshi Imamoto**, Kazuo Haze**, Takeshi Inoue*** and Satoru FujI
}

A rare case of peliosis hepatis associated with idiopathic restrictive cardiomyopathy is reported. A 75-year-old man was admitted for evaluation of marked edema and jaundice. Serum total bilirubin was elevated above $20 \mathrm{mg} / \mathrm{dl}$. The liver biopsy under laparoscopy revealed marked sinusoidal dilatation and retention of red blood cells, which was consistent with a diagnosis of peliosis hepatis. Cardiac catheterization revealed right ventricular filling disturbance without specific findings on endomyocardial biopsy, suggesting idiopathic restrictive cardiomyopathy. The level of serum total bilirubin decreased in association with improvement of edema after drip infusion of furosemide therapy.

(Internal Medicine 37: 51-55, 1998)

Key words: laparoscopy, inferior vena cava venography, cardiac catheterization

\section{Introduction}

Peliosis hepatis is an unusual disorder characterized by multiple blood filled cavities in the hepatic parenchyma. Regarding the etiology of peliosis hepatis, many hypotheses such as congenital malformation (1), androgenic anabolic steroid (2) or oral contraceptive administration (3), and acquired immunodeficiency syndrome (4) have been proposed. On the other hand, restrictive cardiomyopathy is also a rare disorder characterized primarily by abnormal diastolic filling. Here, we report a patient with peliosis hepatis who had idiopathic restrictive cardiomyopathy. The relationship between the two conditions is discussed.

\section{Case Report}

A 75-year-old male patient was admitted to our hospital on November 11, 1996, for evaluation of marked edema and jaundice. He had been well until September 1996 when swelling of the lower legs, dyspnea, and jaundice developed gradually and he was admitted to a local hospital. He used to drink excessively before he quit drinking 25 years ago. The edema disappeared after administration of diuretics, but the cause of edema was undetermined and serum bilirubin remained elevated. He visited our hospital with worsening symptoms after discharge.

On physical examination, there was marked pitting edema in the lower legs. The abdomen was distended and fluid wave was demonstrable. The liver and spleen were not palpable. The penis and scrotum also showed marked edema. The chest was clear to percussion and auscultation.

Laboratory data after admission are summarized in Table 1. Results of urinalysis were normal. Hematological examination revealed mild anemia and a slight decrease in platelet count. Liver function test showed marked elevation of total bilirubin and alkaline phosphatase, moderate serum transferase elevation, and a decrease in serum cholinesterase, total cholesterol, and albumin. Serum electrophoresis disclosed an increase in the gamma globulin fraction. Viral markers for hepatitis B or hepatitis $C$ were all negative. Serologic tests for autoantibodies were all negative.

Chest X-ray film showed no abnormal findings (cardiothoracic ratio $46 \%$ ). The pericardium was not thickened in lateral view. An electrocardiogram showed first degree arterioventricular block with nonspecific ST-segment and Twave changes. Abdominal ultrasound and computed tomography (CT) scan revealed dilatation of inferior vena cava and hepatic vein, and small amount of ascites was detected. There was no evidence to substantiate a diagnosis of liver cirrhosis or obstructive jaundice on radiographic examination. An

From the Department of Internal Medicine, *the Department of Gastroenterology, **the Department of Cardiology and ***the Department of Pathology, Osaka City General Hospital, Osaka

Received for publication June 20, 1997; Accepted for publication October 8, 1997

Reprint requests should be addressed to Dr. Katsunobu Yoshioka, the Department of Internal Medicine, Osaka City General Hospital, 2-13-22, MiyakojimaHondori, Miyakojima, Osaka 534 
Table 1. Laboratory Data on Admission

\begin{tabular}{lrlr}
\hline Urinalysis & n.p. & Y-glutamyl transpeptidase & $95 \mathrm{IU} / \mathrm{l}$ \\
Peripheral blood & & Thymol turbidity test & $5.2 \mathrm{Kun}-\mathrm{U}$ \\
White blood cell count & $3,920 / \mathrm{mm}^{3}$ & Zinc sulfate turbidity test & $15.9 \mathrm{Kun}-\mathrm{U}$ \\
Red blood cell count & $378 \times 10^{4} / \mathrm{mm}^{3}$ & Blood urea nitrogen & $16.5 \mathrm{mg} / \mathrm{dl}$ \\
Hemoglobin & $11.7 \mathrm{~g} / \mathrm{dl}$ & Creatinine & $0.8 \mathrm{mg} / \mathrm{dl}$ \\
Hematocrit & $36.7 \%$ & Total cholesterol & $133 \mathrm{mg} / \mathrm{dl}$ \\
Platelet & $11.8 \times 10^{4} / \mathrm{mm}^{3}$ & Fasting plasma glucose & $77 \mathrm{mg} / \mathrm{dl}$ \\
Prothrombin time & $52.5 \%$ & Ammonia & $86 \mu \mathrm{g} / \mathrm{dl}$ \\
Hepaplastin test & $22.6 \%$ & & \\
Blood Chemistry & & Serological test & \\
Total protein & $5.7 \mathrm{~g} / \mathrm{dl}$ & C-reactive protein & $(.53 \mathrm{mg} / \mathrm{dl}$ \\
albumin & $48.0 \%$ & Hepatitis B surface antigen & $(-)$ \\
$\alpha_{1}$ & $3.2 \%$ & Hepatitis B surface antibody & $(+)$ \\
$\alpha_{2}$ & $6.6 \%$ & Hepatitis B envelope antigen & $(-)$ \\
$\beta$ & $10.4 \%$ & Hepatitis B envelope antibody & $(+)$ \\
$\gamma$ & $31.8 \%$ & Hepatitis B Viral DNA & $(-)$ \\
Total bilirubin & $6.2 \mathrm{mg} / \mathrm{dl}$ & Hepatitis B Viral polymerase & $(-)$ \\
Direct bilirubin & $3.9 \mathrm{mg} / \mathrm{dl}$ & Hepatitis C antibody & $(-)$ \\
Asparate aminotransferase & $58 \mathrm{IU} / l$ & Antinuclear antibody & $\times 20$ \\
Alanine aminotransferase & $31 \mathrm{IU} / l$ & Anti-mitochondrial antibody & $(-)$ \\
Alkaliphosphatase & $539 \mathrm{IU} / l$ & Anti-smooth muscle antibody & $(-)$ \\
Lactate dehydrogenase & $272 \mathrm{IU} / l$ & & \\
Cholinesterase & $71 \mathrm{IU} / l$ & & \\
& & &
\end{tabular}

echocardiogram showed no abnormal findings except for first degree tricuspid valve regurgitation.

All medication was discontinued to rule out drug-induced hepatitis. However, bilirubin progressively elevated above 15

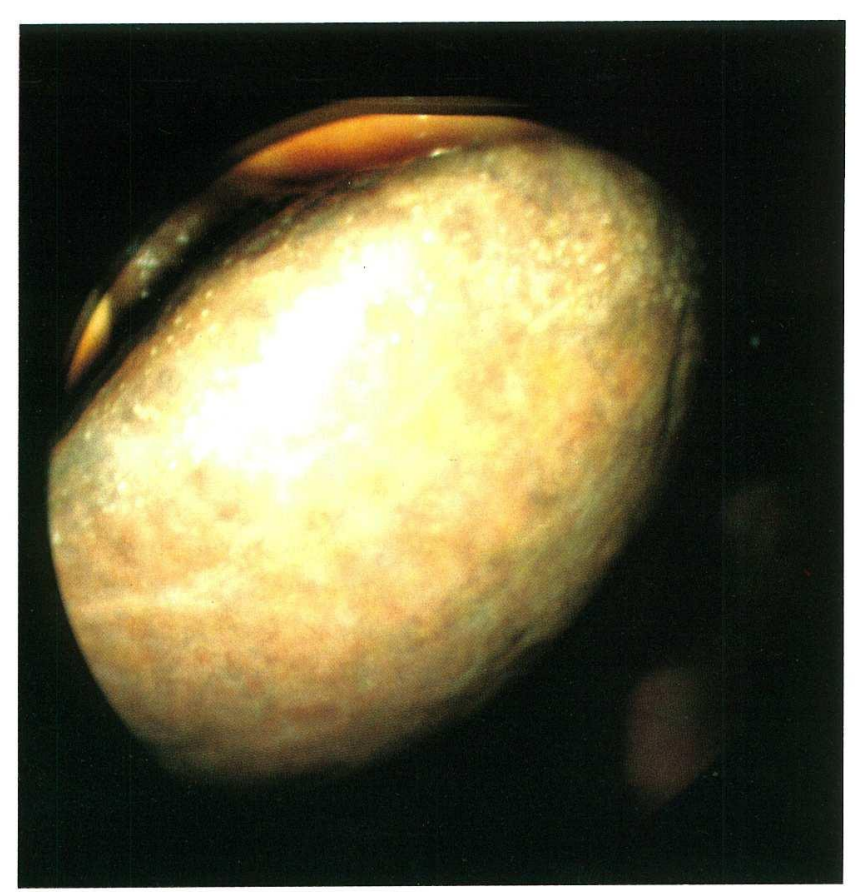

Figure 1. Laparoscopic examination, showing dark brown liver with scattered dark red spots. $\mathrm{mg} / \mathrm{dl}$. Thus, laparoscopy was performed for further examination. The laparoscopy showed dark brown liver with scattered dark red spots (Fig. 1). The liver biopsy specimen revealed marked sinusoidal dilatation and retention of red blood cells (Fig. 2). Fibrosis and infiltration of inflammatory cells were not seen. Marked sinusoidal dilatation was observed only in part of the biopsy specimen obtained (Fig. 3). Silver stain of the specimen showed disruption of reticulin framework (Fig. 4). These laparoscopic and pathologic findings were consistent with a diagnosis of peliosis hepatis.

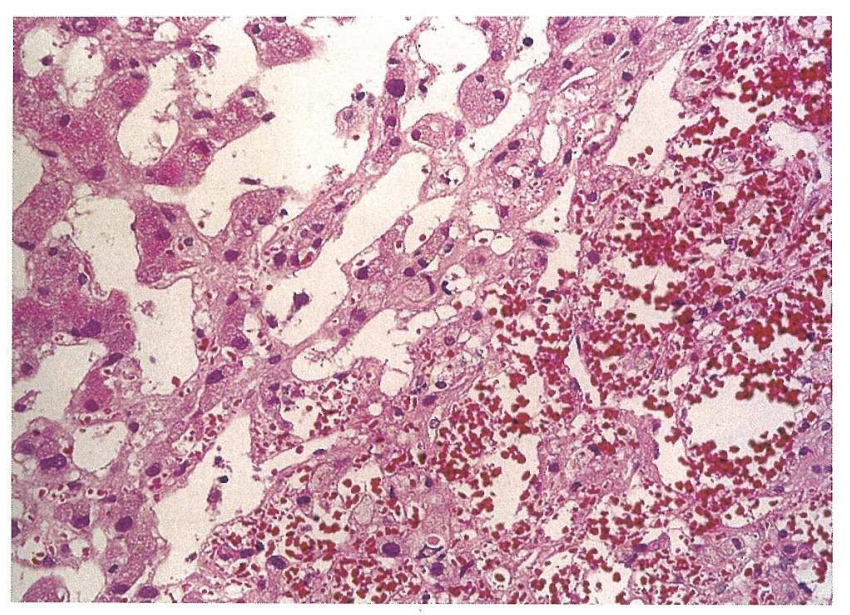

Figure 2. Light microscopic appearance of $\mathrm{HE}$ stain of the liver biopsy specimen with higher magnification $(\times 200)$ showing marked sinusoidal dilatation and retention of red blood cells. 


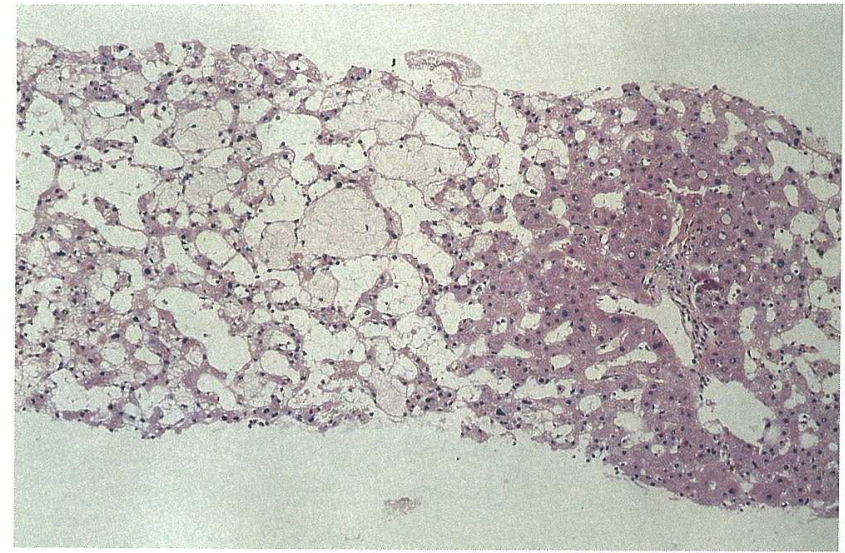

Figure 3. Light microscopic appearance of HE stain of the liver biopsy specimen with lower magnification $(\times 40)$ showing that sinusoidal dilatation was observed only in part of the specimen.

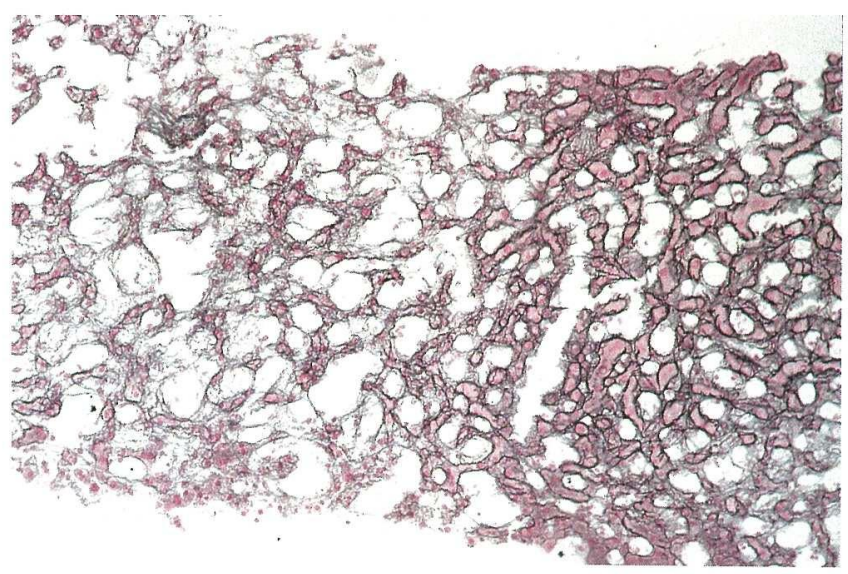

Figure 4. Silver stain of the liver biopsy specimen showing disruption of reticulin framework $(\times 60)$.

Inferior vena cava venography, which was performed to rule out obstruction to venous outflow, revealed marked regurgitation from the inferior vena cava into the hepatic vein (Fig. 5). Right-sided and left-sided cardiac catheterization was per-

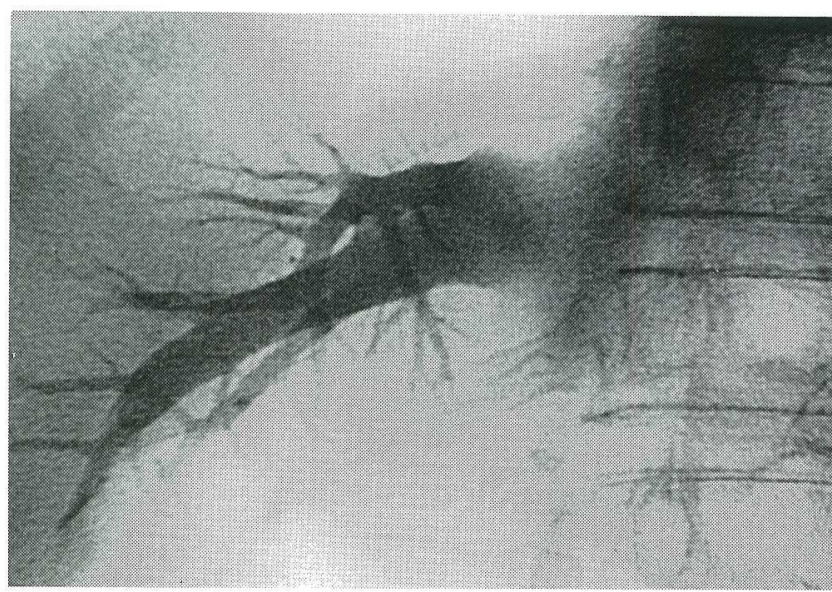

Figure 5. Inferior vena cava venography showing marked regurgitation from inferior vena cava into hepatic vein.

Table 2. Hemodynamic Measurements

Heart rate

Aorta (systolic/diastolic)

Left ventricle (systolic/diastolic/mean)

Right ventricle (systolic/diastolic/mean)

Right atrium (mean)

Inferior vena cava

Pulmonary artery (systolic/diastolic)

Pulmonary capillary wedge

Cardiac index
67 (beat/min)

92/58 ( $\mathrm{mmHg})$

94/3/15 ( $\mathrm{mmHg})$

$27 / 11 / 13(\mathrm{mmHg})$

$13(\mathrm{mmHg})$

$13(\mathrm{mmHg})$

23/15 ( $\mathrm{mmHg})$

$12(\mathrm{mmHg})$

$1.8\left(1 / \mathrm{min} / \mathrm{m}^{2}\right)$

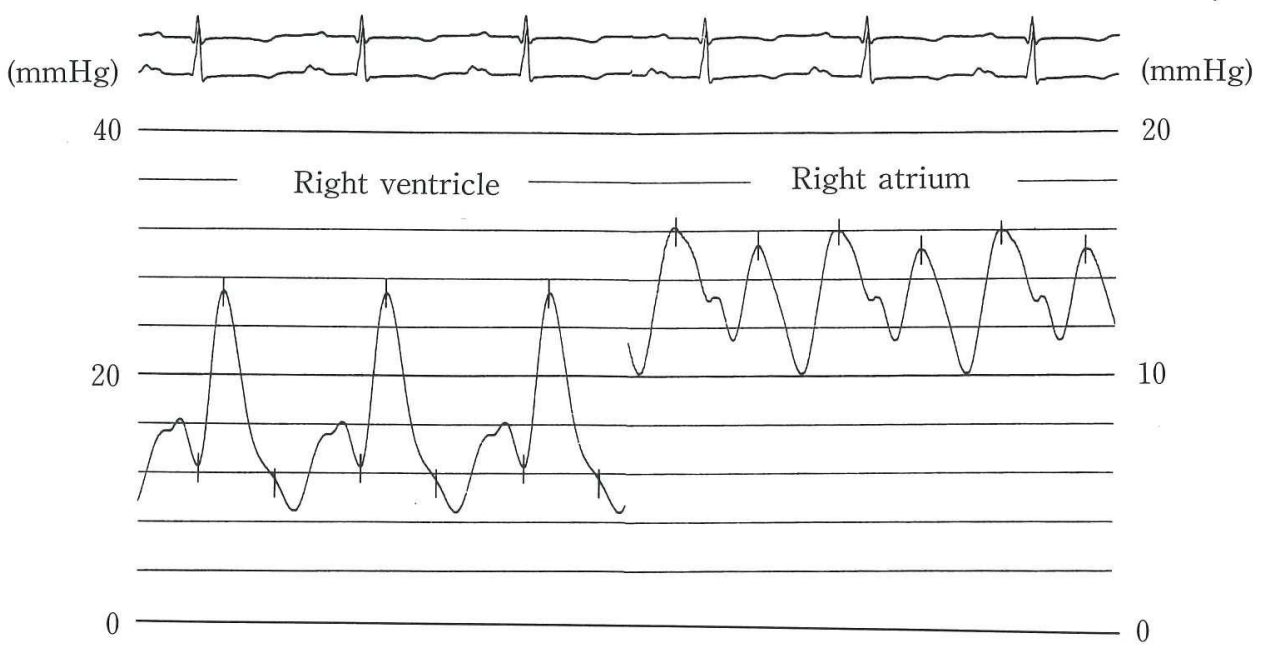

Figure 6. Pressure curve from the left atrium and the right ventricle. 
YosHIOKA et al

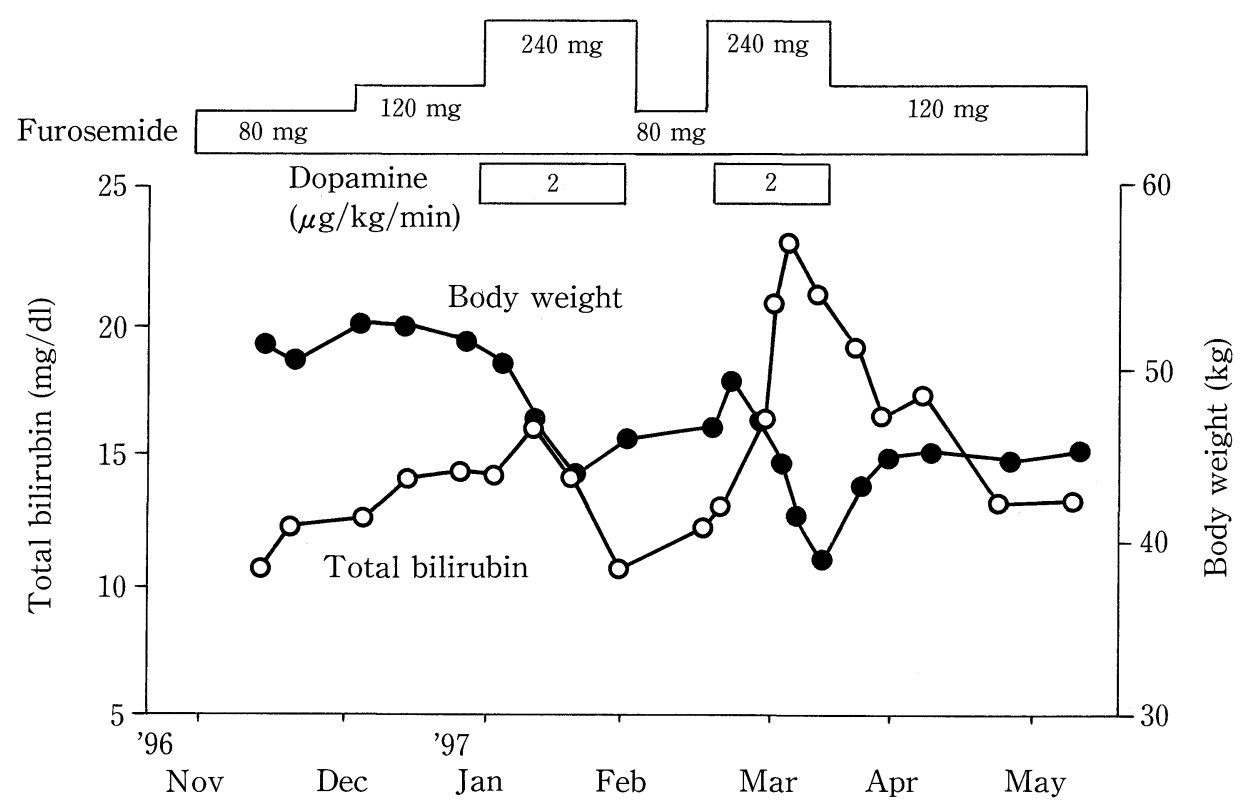

Figure 7. Clinical course.

formed to observe cardiac function (Table 2). Coronary and a left ventricular angiographic examinations were normal. Although the pressure curve from the right ventricle did not show the typical dip and plateau pattern, the pressure curve from the right atrium showed prominent $\mathrm{x}$ and $\mathrm{y}$ descents (w shape), suggesting that the right ventricular filling was disturbed (Fig. 6). Endomyocardial biopsy was performed, but no specific finding was obtained. Congo red stain was negative. These results indicate a diagnosis of peliosis hepatis associated with idiopathic restrictive cardiomyopathy.

After drip infusion of furosemide $(240 \mathrm{mg} /$ day) together with a small dose of dopamine $(2 \mu \mathrm{g} / \mathrm{kg} / \mathrm{min})$, the leg edema gradually decreased and subsequently the bilirubin level decreased to $10 \mathrm{mg} / \mathrm{dl}$ (Fig. 7). However, after discontinuing drip infusion, the leg edema increased and subsequently bilirubin became elevated above the level of $20 \mathrm{mg} / \mathrm{dl}$. Drip infusion of furosemide and dopamine were administered again, which decreased edema and bilirubin in the same way. He is now treated with an injection of $40 \mathrm{mg}$ of furosemide once a day together with $120 \mathrm{mg}$ of furosemide orally, and the level of bilirubin has stabilized at about $10 \mathrm{mg} / \mathrm{dl}$.

\section{Discussion}

Though several hypotheses have been proposed, the mechanism of peliotic cavity formation is not clear. Ultrastructural lesions of the liver suggest that primary alterations of the sinusoidal barrier and secondary changes to increased pressure and hypoxia contribute to the formation of peliotic cavity (5).

Longstanding right-sided heart failure due to cardiomyopathy or pericardial constriction may lead to liver abnormalities which resemble our case. The fact that the level of serum bilirubin decreased in association with improvement of edema suggests that liver congestion contributed to liver abnormalities in the present case. However, cardiac cirrhosis shows striking congestion and centrizonal necrosis followed by linking of central zones with fibrosis. In this case, fibrosis was not seen and marked sinusoidal dilatation was observed only in part of the biopsy specimen obtained, which makes the diagnosis of cardiac cirrhosis unlikely. Thus, it is unlikely that liver congestion was the primary cause of liver abnormalities. There are two different types of peliosis hepatis: the original parenchymal type in which the blood cysts are not distinctly lined; and the phlebectatic type with endothelial or fibrous lining (6). Silver stain showed disruption reticulin framework, which may classify our case as the phlebectatic type. However, the division between the 2 types may not be as clear as suggested above and both types may be present in the same patient. Peliosis hepatis is potentially reversible to a certain degree unless serious underlying conditions exist (7). Though the primary cause of peliotic cavity formation in the present case is still uncertain, it is assumed that underlying restrictive cardiomyopathy and subsequent liver congestion made the peliotic changes irreversible.

Despite the application of a variety of hemodynamic criteria (8), distinguishing constrictive pericarditis from restrictive cardiomyopathy is difficult. Since constructive pericarditis is a surgically curable disease, the distinction is of clinical importance. Endomyocardial biopsy has proven useful in establishing the diagnosis of specific forms of restrictive cardiomyopathy such as amyloidosis (9). However, in patients without specific pathologic findings, the need for surgical interventions must be considered. Imaging technologies such as $\mathrm{CT}$ scanning (10) or magnetic resonance imaging (MRI) (11) appear to be a sensitive means of detecting an abnormal pericardium. The present patient was diagnosed as having restrictive cardiomy- 


\section{Peliosis and Restrictive Cardiomyopathy}

opathy because neither CT scanning nor MRI detected a thickened pericardium. Thus, a thoracotomy was not performed.

In summary, we encountered a case of peliosis hepatis associated with idiopathic restrictive cardiomyopathy. The level of serum total bilirubin decreased in association with improvement of edema. Liver biopsy under laparoscopy was useful for differential diagnosis. A diagnosis of peliosis hepatis should be included in the differential diagnosis of patients with jaundice.

\section{References}

1) Weir MR, Decherd J, Beathard G. A unique case of peliosis hepatis. Tex Rep Biol Med 27: 1105, 1969.

2) Nadell J, Kosek J. Peliosis hepatis. Twelve cases associated with oral androgen therapy. Arch Pathol Lab Med 101: 405, 1977.

3) Ockner RK, Davidson CS. Hepatic effects of oral contraceptives. N Engl J Med 276: 331, 1967.

4) Czapar CA, Weldon-Linne CM, Moore DM, Rhone DP. Peliosis hepatis in the acquired immunodeficiency syndrome. Arch Pathol Lab Med 110:
611,1986

5) Zafrani ES, Cazier A, Baudelot AM, Feldmann G. Ultrastructural lesions of the liver in human peliosis. A report of 12 cases. Am J Pathol 114: 349, 1984.

6) Yanoff M, Rawson A. Peliosis hepatis - An anatomic study with demonstration of two varieties. Arch Pathol 77: 159, 1964.

7) Bagheri SA, Boyer JL. Peliosis hepatis associated with androgenicanabolic steroid therapy. A severe form of hepatic injury. Ann Intern Med 81: 610, 1974.

8) Vaitkus PT, Kussmaul WG. Constrictive pericarditis versus restrictive cardiomyopathy: a reappraisal and update of diagnostic criteria. Am Heart J 122: 1431, 1991.

9) Schoenfeld MH, Supple EW, Dec GW Jr, Fallon JT, Palacios IF. Restrictive cardiomyopathy versus constrictive pericarditis: role of endomyocardial biopsy in avoiding unnecessary thoracotomy. Circulation 75: 1012, 1987.

10) Sutton FJ, Whitley NO, Applefeld MM. The role of echocardiography and computed tomography in the evaluation of constrictive pericarditis. Am Heart J 109: 350, 1985.

11) Soulen RL, Stark DD, Higgins CB. Magnetic resonance imaging of constrictive pericardial disease. Am J Cardiol 55: 480, 1985. 